\title{
The Impact of Covid-19 Pandemic on Consumer Purchase Behavior
}

\author{
Ran Chen ${ }^{1, \dagger}$, Yue Hang ${ }^{2, \dagger}$, Jingwen Yan ${ }^{3, *}, \dagger$ \\ ${ }^{1}$ Nanjing Jinling High School Hexi Campus, 210005 Nanjing, China \\ ${ }^{2}$ Senior School, Wuhan Britain-China School, 430060 Wuhan, China \\ ${ }^{3}$ St Johns Senior School, North Loge, EN2 8EB London, England \\ *Corresponding author: stjohnssc@aol.com \\ †These authors contributed equally.
}

\begin{abstract}
Due to the blowout of COVID-19, a great variety of businesses suffered from a decrease in revenue, among which is one of the most popular industries today-online shopping. People's purchasing and consumption habits have shifted as the corona virus epidemic has progressed. As a result of the epidemic, not only have purchasing habits changed but so have sales-force operations. Recently, a lot of articles have been published about virus infection prediction and consumer behavior research in different countries. These articles analyze using mathematical modeling and a diverse set of data. In this paper, we will review these mathematics models and analyze the trend and the degree to which the online shopping market was affected by COVID-19 according to a different region in China, different kinds of products. The main criteria we are going to look at is how did the sales decreased or increase by percentage compared with the sales in the last few years.
\end{abstract}

Keywords: COVID-19; shopping pattern; mathematical modelling; SIR; SRID.

\section{Introduction}

At the beginning of 2020, there appears the most popular and significant virus named Covid-19 which causes many people to get an infectious illness and lead people dead directly. Under this situation, the government published policies to prevent widespread infection and asked individuals do not to go out, every institution has to be closed or work online except for essential hospitals and supermarkets which can be opened. It causes many firms can not to operate. However, there are many changes in online shopping. Government plays an important role to solve this series of problems with subsidies to them. Because people cannot go shopping in the real shops, and there are already lots of shops online that can offer goods and services. This essay is going to describe the changes because of Covid-19 about individuals' behaviors and attitudes about online shopping with data analysis. Using secondary research, totally 3 parts at all, namely the impact in China. Because of the breakout of corona virus, people's habit of shopping has been greatly influenced. In order to get COVID-19 under control, many countries, including China when the virus spread out most seriously, have enacted regulations that required citizens to stay at home. Therefore, many offline shopping malls, supermarkets, grocery stores, and all kinds of different physical stores suffer from the prohibition of coming out. Apart from that, in order to prevent themselves from being injected, many people's preferences while shopping have been altered. Some medical supplies, such as facial masks, gloves, alcohols for killing bacteria, and so on, were becoming increasingly popular due to the corona virus. In addition, the sales of goods that are not necessities dropped significantly, as the majority of people were laying emphasis on the burst out of the epidemic. Therefore, the spreading out of the epidemic showed a determining effect on the preferences of customers while shopping. With the high infection by the CPVID-19, the government became to enact large-scale isolation policies across the world, and then the scientists established a Math modeling about the spread of COVID-19. In this computational models must consider the effect in economics by the mitigation measures and it also takes into account the ages aspects. So I think the best way to increase the economics during the isolation is to agitate people to spend money online. There was data about the situation of the economy. 
We can see that by the end of the simulation, the economy shrinks by $32.3 \%$. By the article of Na Hao and her group members, we found that the fresh food channels are more likely to have panic stockpile behaviors because of government assistance. This panic can be shown that with the development of pandemics, people are more reliant on online ways. If people failed to order, they can hardly switch to offline channels, which can cause the panic of the food. They also investigated that even the elderly people tended to shop the grocery in online channels and then store them. (Na Hao, 2018).

\section{The impact of COVID-19 on consumption}

Purchasing and consumption habits of people have shifted as the corona virus epidemic has advanced [1]. Not only have purchasing habits changed as a result of the epidemic, but so have salesforce operations [1]. Eventually, a new corona virus was discovered in Wuhan, China. When people started to be aware of the danger of corona virus, consumers concentrated on panic buying to reduce the danger of future shortages during the pandemic [2]. There have been several reports of panic buying non-perishable food items (e.g., pasta, canned goods, rice, wheat, frozen foods) around the world. According to [3], panic purchasing is a frequent human response to a crisis triggered by a fear of simply running out of food rather than food scarcity.

The pandemic has had a detrimental impact on consumption across a variety of market segments in China [4]. In China, panic purchasing was uncommon. According to Statista (2021), 26\% of respondents in China acknowledged panic shopping, primarily for dry food and hygiene products. Some shoppers stock food to cut down on future shopping excursions by purchasing more items on each trip to avoid store visits and, as a result, lower their potential risk of COVID-19 exposure [5]. Therefore, the government in China started to encourage people to online shopping during this pandemic to avoid any panic buying behavior as well as reduce the risk of getting Covid-19. With the emergence of COVID-19, this change in purchasing behavior has accelerated significantly, forcing businesses to reach out to even their most devoted brick-and-mortar customers online. People in China started to purchase all items online as China has various e-commerce platforms such as Ali Express, TMall.com, JD.com, Taobao.com, etc. These platforms have provided a variety of products and services for customers. Consumer purchasing habits are shifting away from conventional retail and toward online shopping [6]. Instead of purchasing trendy items, most buyers have begun to order more basic care, medical items, and food online.

The most essential approach for containing the pandemic is to eliminate possibilities for humanto-human transmission. The effectiveness of China's fight against the pandemic is inextricably linked to the entire country's collaboration and residents' voluntary seclusion at home. According to Digital (2020), 55\% of respondents in China are more likely to shop online during the pandemic [7]. This pandemic scenario has been categorized into two aspects: the first is a shift in consumer behavior that minimizes crowded public meetings, and the other is a greater willingness to use digital technology (Shashidhar, 2020). According to Statista (2021), 74\% of the Chinese respondents said they bought groceries online more frequently than before the Covid-19 outbreak. Meanwhile, around $21 \%$ of Chinese respondents raised their online grocery shopping spending during the Covid-19 pandemic.

Additionally, the epidemic has expedited significant structural changes throughout the world, particularly in commercial digital transitions [8]. When most Chinese were restricted to going out from home, the usage of mobile has rose which is 7.3 hours per day per user. There was an increase of more than one hour if compared with the period before Covid-19. According to a Statista report (2020), there were around $69 \%$ of the catering enterprise or restaurants have lost their dine-in customers which about $80 \%$ in China. The main reason that people are concerned is about the infection and sanitation of the catering enterprise after the outbreak of Covid-19. Therefore, most of the restaurants in China also have to change their business model from dine-in service to food delivery to cope with this changing purchase behavior during pandemic Covid-19 [9]. Most of the companies will apply an Eating stream as known as "Mukbang" on the TikTok application as one of the 
marketing tools to promote their foods during pandemic Covid-19. (Choe, 2019: 171). For instance, Haidilao is one of the famous Chinese hotpots that has successfully generated revenue by having this kind of Mukbang via Douyin (Graziani, 2018). In China, there have various online food-delivery companies such as Elle. Me, ENJOY, Daojia, Meituan Dianping, Home-cook, etc, that provide fast delivery services to customers. This influenced customer purchase behavior where customers tend to use food delivery services through online food-delivery companies rather than dine-in in restaurants during this Covid-19 pandemic.

\section{Mathematics model of the COVID-19 outbreak}

The process of finding out a method to analyze the influence of COVID-19 on consumers' behavior is quite difficult. The COVID-19 pandemic has created a new world that is more complex and completely different from what we have known to date. And to identify these changes in consumer behavior, it was practical to distribute a structured questionnaire in January and February 2021 via social networks and mail. This method was utilized by Katarina Valaskova, Pavol Durana, and Peter Adamko. The method being used as the inverse square root method, accepting a significance level of 0.05 and a confidence level of 0.95 . First of all, this questionnaire divided respondents into different groups of people according to their age groups and gender. With demographic information in hand, monthly income was then taken into consideration, based on the assumption that the higher the income, the lower the negative impact the crisis had. In addition, the employment rate and different kinds of occupation or sectors were also analyzed, as these can also affect people's behavior to a great extent [10].

Personally, the positive point of this experiment is that it did take a great variety of variables-including gender, age, and occupation - into consideration, which overcome a disadvantage of those research that only look for the value of total revenue, for example. Only looking at some general values is likely to make researchers ignore some important details that play a key role in changing consumers' behavior, and it can only provide some limited results, presenting difficulties on further research. Apart from that, this analysis was aimed at determining the relationships between categories of specified variables which are arranged in contingency tables, which make sure that every factor being considered can be focused on independently, to prevent the loss of any valuable outcomes. By comparison, the main drawback of this analysis is that it failed to take respondents' preferences while shopping into account. While it is true that a person's age, gender, and occupation can provide some general trend about his/her probability to switch the pattern of purchasing goods, his/her preference or habits can play an equally, or even more important role. The stereotype is that people in some particular occupations are likely to buy some specific goods, but sometimes exceptions do exist [11]

And here are some mathematical models that can be utilized. Model SRID (Susceptible susceptible, recovered - recovered, Infectious - infected, deceased - dead). This model can use a sliding window to predict the rates of mortality and recovery, and the window can last for a whole day. The estimation is made in the situation that urgent measures are taken to overcome the epidemic. Diego Caccavo used a modified version of the SIRD model to make descriptions of Chinese and Italian COVID-19 outbreaks. The model has assumed that the amount of people for reference is unchanged ( $\mathrm{N}=60$ million), which means that the rate of birth \& death (including deaths caused by COVID-19) are the same, and another assumption is that people who recovered will not be infected a second time. Then, Caccavo wrote these differential equations he had with people's initial conditions, and they represent And eventually, Caccavo managed to the number of people who were confirmed, infected, recovered, and killed(by the virus). He suggests that the main advantage of the model is that it can show the kinetic of infection, and give useful insight based on physical-based assumptions [12].

Model SIR (Susceptible - susceptible, Infectious - infected, Recovered - recovered). This model gives a forecast of possible outbreaks of COVID-19 and how should people control them. A model with the formation of stable immunity. The model is expressed using stochastic differential equations. 
Modeling is performed by changing exposure factors over time to understand the response of infection to blocking a schedule of more than 6 months. Impact factor: isolation, selective quarantine, and preventive measures. The exposure coefficient, which models interventions to suppress transmission of infection, is also taken into account $[12,13]$. In their paper, Erhan Bayraktar, Asaf Cohen, and April Nellis made use of this modeling method, and they divided participants into different groups concerning their ages, categorizing them as either low-risk or high-risk due to different situations. After that, the percentage of high-risk and low-risk group people are both analyzed, and some specific people in the latter group were maybe prone to contract cases of COVID19 [13].

However, the disadvantage is mostly the short lead-time. And the second drawback of reproductive number is not included in the model, although it can be calculated. The model is not particularly simple, to obtain accurate results using SIR models, in-depth information on social movements is necessary and quality of lock down measures will be important. Lead-time increases, the accuracy of the model declines. In general, SIR-based models will be accurate.

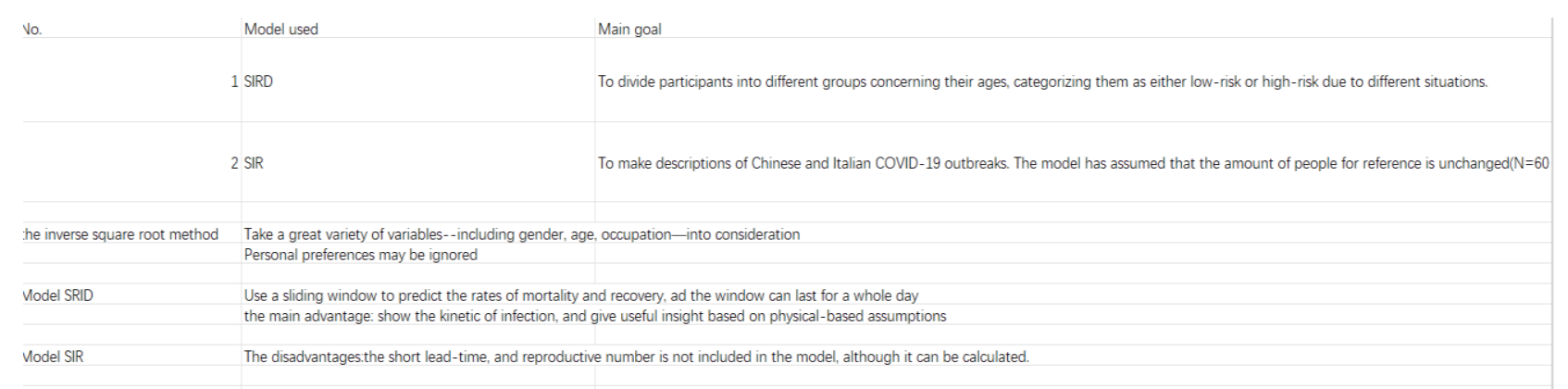

Figure 1. The comparison of different models

\section{Mathematics model of the online shopping businesses impact}

With the multiple spread of the pandemics virus, the COVID-19 caused radical changes in the lifestyle of people around the world (Saadat et al. 2020) [14]. The most significant impact on the economy on the pandemic was the decrease in production and causing problems by the distribution of food and medical and financial impact on the market. (Guan et al. 2020). Since in the aspect of energy management, it is very important to improve the environment among the global [15]. From the perspective of general, energy consumption has decreased (Senthilkumar et al. 2020). Therefore, the future line can be increased energy efficiency [16]. Furthermore, the problem about the expansion of the world, for example, the plan of neighborhoods in 20 minutes, was proposed to meet the cities' need to reduce energy consumption and pollution (Reimer 2020) [17]. So converting the way shopping in the malls to online ways can be more reasonable and support, since it can help people to get the services and goods more easily, which also grants the protection of the supply chain affected by the pandemics. For example, in some fields, they can join to use reusable protective equipment and appropriately select the disinfection technology, so that the energy can be decreased in cost, pollution, and energy consumption. As the result, by the changing in the strategy about online shopping, people need to save energy and then we can have an increase in the GDP.

With the high infection by the CPVID-19, the government became to enact large-scale isolation policies across the world, and then the scientists established a Math modeling about the spread of COVID-19. In this computational models must consider the effect in economics by the mitigation measures and it also takes into account the ages aspects. So I think the best way to increase the economics during the isolation is to agitate people to spend money online. There was data about the situation of the economy. We can say that by the end of the simulation, the economy shrinks by $32.3 \%$ [18]. By the article of $\mathrm{Na} \mathrm{Hao} \mathrm{and} \mathrm{her} \mathrm{group} \mathrm{members,} \mathrm{we} \mathrm{found} \mathrm{that} \mathrm{the} \mathrm{fresh} \mathrm{food} \mathrm{channels} \mathrm{are}$ more likely to have panic stockpile behaviors because of government assistance. This panic can be shown that with the development of pandemics, people are more reliant on online ways. If people 
failed to order, they can hardly switch to offline channels, which can cause the panic of the food. They also investigated that even the elderly people tended to shop the grocery in online channels and then store them. (Na Hao, 2018).

To be more specific in the students. When the pandemic spread, the schools introduced measures to minimize social interactions and reduce exposures to better protect the students. The schools adopt online courses and the students can get more rapid information [19]. And students also did some online leisure time and both the business activities (Educase 2021). The time the students used in the online network was increasing due to the pandemics. As the result, by the elaboration and the investigation from the author in this passage, we can conclude that the pandemic can be thought to have few benefits in energy and economics.

\section{Conclusion}

In summary, we focus on the mathematics model study during the outbreak of COVID-19 and the impact on consumer behavior, especially online shopping. With the high infection by the CPVID-19, the government became to enact large-scale isolation policies across the world. Customers tend to use delivery services through online food-delivery companies rather than dine-in in restaurants during this Covid-19 pandemic. Then, different mathematics models are analyzed in this paper including SRID and SIR. These models are used to predict the rates of mortality and recovery and the impact on the online shopping business. Economic devastation is mounting with a global depression now seeming inevitable. Governments of different countries could introduce some policies to help and support the development of social industries, including the digital economy, online consumption, and distance education

\section{References}

[1] Hartmann N N, Lussier B. Managing the sales force through the unexpected exogenous COVID-19 crisis [J]. Industrial Marketing Management, 2020, 88: 101-111.

[2] Beard-Knowland, T. (2020). The Impact of Covid-19 on How We Eat. 2020.

[3] Grasso, S. (2020). Consequences of Panic Buying, IFNH.

[4] Chen H, Qian W, Wen Q. The impact of the COVID-19 pandemic on consumption: Learning from highfrequency transaction data[C]//AEA Papers and Proceedings. 2021, 111: 307-11.

[5] Cranfield J A L. Framing consumer food demand responses in a viral pandemic [J]. Canadian Journal of Agricultural Economics/Revue canadienne d'agroeconomie, 2020, 68(2): 151-156.

[6] Reddy, A. (2020). Covid-19 impact: Consumers move more towards digital. Business Line.

[7] Fedorko R, Král' Š. Online Shopping Problems in the Context of B2C E-commerce in the Visegrad Four Countries[C] Digital Marketing \& eCommerce Conference. Springer, Cham, 2021: 83-94.

[8] Kim R Y. The impact of COVID-19 on consumers: Preparing for digital sales [J]. IEEE Engineering Management Review, 2020, 48(3): 212-218.

[9] Babenskaite G, Yang M. Mukbang Influencers: Online eating becomes a new marketing strategy: A case study of small sized firms in China's food industry [J]. 2019.

[10] Valaskova K, Durana P, Adamko P. Changes in consumers' purchase patterns as a consequence of the COVID-19 pandemic[J]. Mathematics, 2021, 9(15): 1788.

[11] Mustafa S K, Ahmad M A, Sotnik S, et al. Brief review of the mathematical models for analyzing and forecasting transmission of COVID-19[J]. 2020.

[12] Caccavo D. Chinese and Italian COVID-19 outbreaks can be correctly described by a modified SIRD model [J]. MedRxiv, 2020.

[13] Bayraktar E, Cohen A, Nellis A. A macroeconomic SIR model for COVID-19[J]. Mathematics, 2021, 9(16): 1901.

[14] Saadat S, Rawtani D, Hussain CM. Environmental perspective of COVID-19. Sci Total Environ 2020, 728:138870. 
[15] Guan WJ, Ni ZY, Hu Y, Liang WH, Ou CQ, He JX, Zhong NS. Clinical characteristics of coronavirus disease 2019 in China. N Engl J Med, 2020, 382(18):1708-1720.

[16] Senthilkumar V S, Reddy K S, and Subramanian U. COVID-19: Impact analysis and recommendations for power and energy sector operation [J]. Appl. Energy, 2020, 279: 115739.17.

[17] Reimer J, The 15-minute infrastructure trend that could change public transit as we know it. Accessed 9 Mar 2021

[18] Hao N, Wang H H, Zhou Q. The impact of online grocery shopping on stockpile behavior in Covid-19[J]. China Agricultural Economic Review, 2020.

[19] Educase, 2021. A Day in the Online Life of a Student, [online] Available at: [Accessed 10 April 2021]. 